\title{
PROCESSAMENTO DE ALIMENTOS NÃO CONVENCIONAIS: FABRICAÇÃO DE MOLHO DE TOMARINDO (Tamarindus indica)
}

\section{PROCESSING OF NON-CONVENTIONAL FOODS: MANUFACTURE OF TAMARINDO SAUCE (Tamarindus indica)}

\author{
Kelly Silva Pinheiro'; Vitória Letícia Silva dos Santos²; Flávia Rayane Carvalho \\ Sousa $^{3}$; Leandro Rodrigo Everton ${ }^{4}$; Diana Maria Cano Higuita ${ }^{5}$
}

DOI: https://doi.org/10.31692/978-65-991061-7-0.508-511

\section{INTRODUÇÃO}

O tamarindeiro (Tamarindus indica L.) é uma árvore frutífera da família leguminosae (Caesalpinioideae) de origem africana, mas que se expandiu em vários outros países de clima tropical e subtropical. Seu fruto é protegido por uma vargem alongada que tem casca de cor marrom e quebradiça, o qual, no seu interior, podemos encontrar uma polpa de cor escura ou parda, cujo sabor agridoce estimula as glândulas salivares (SANTOS,2010). A fruta, madura e seca, contém principalmente ácido tartárico, açúcares redutores, pectina, tanino, fibra e celulose. As sementes inteiras também contêm proteínas, gorduras, açúcares e carboidratos. Tanto a polpa quanto as sementes são boas fontes de potássio, cálcio e fósforo e contêm outros minerais como sódio, zinco e ferro sendo destacado como o mais azedo de todos os frutos. (Saideswara Rao e Mary Mathew, 2012)

Imagem 1: vargem da tamarindo. Fonte: http://formasaudavel.com.br/tamarindo/.

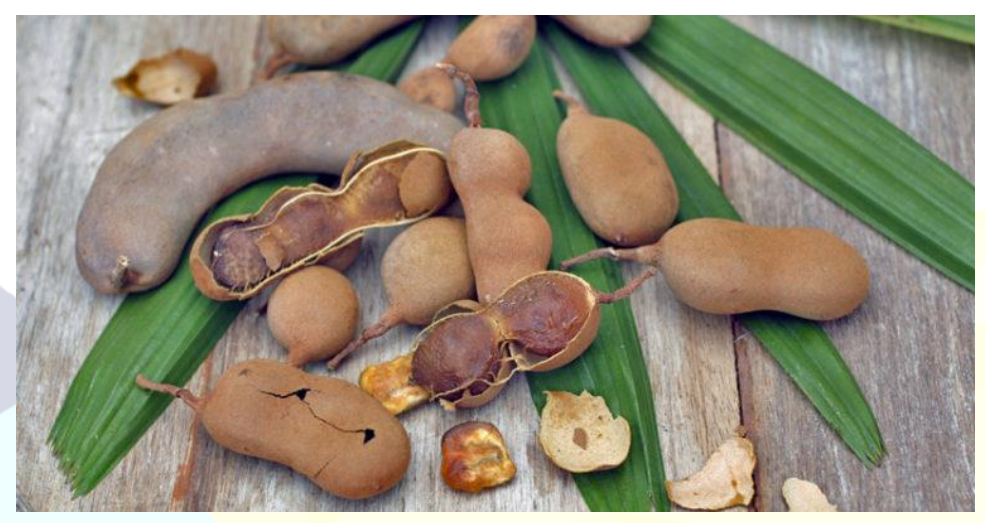

A polpa da tamarindo é rica em ácidos orgânicos como tartárico, cítrico, málico e ascórbico, sendo destacado como o mais azedo de todos os frutos (MAIA et al., 2014).

O fruto da tamarindo pode ser consumido in natura ou sua polpa pode ser processada

\footnotetext{
${ }^{1}$ Tecnologia de Alimentos, Instituto Federal do Maranhão Campus Codó (IFMA), kellyksp1@ @mail.com

2 Tecnologia de Alimentos, Instituto Federal do Maranhão Campus Codó (IFMA), vvleticiasanttos@gmail.com

3 Tecnologia de Alimentos, Instituto Federal do Maranhão Campus Codó (IFMA), flaviarayane32@ gmail.com

4 Tecnologia de Alimentos, Instituto Federal do Maranhão Campus Codó (IFMA), leandro_everton@hotmail.com

5 PhD Engenharia de Alimentos, Instituto Federal do Maranhão Campus Codó (IFMA), diana.higuita@ifma.edu.br
} 
para fabricação de sucos e outros produtos, além disso por ser uma fruta muito aceita sensorialmente pela população e por sua composição química foi elaborado um molho de tamarindo para ser utilizado em carnes fritas e assadas na aula prática da disciplina de Tecnologia de Produtos de Origem Vegetal I.

\section{RELATO DE EXPERIÊNCIA}

No mundo em que vivemos, onde a população corre contra o tempo e as comidas prontas ou que são fáceis e rápidas no preparo, vão tomando lugar de comidas saudáveis e caseiras. Outro fator a se questionar nesse tempo é o crescente desperdício de alimentos que acaba muitas vezes poluindo nosso planeta, não o bastante, pessoas vivem em miséria e morrem de fome por não ter o que comer. Por isso, se torna muito importante o trabalho de pesquisadores que buscam novas fontes de alimentos, principalmente de produtos não convencionais, ou seja, utilizar o que muitas vezes é descartado para o processamento de alimentos inovadores.

Inicialmente, a polpa ficou descongelando parcialmente e em seguida foi medida a quantidade de polpa (380mL), a quantidade de açúcar (280g), e o amido (100g). Numa panela de alumínio, que foi levada ao fogo, utilizou-se fios de óleo $(15 \mathrm{~mL})$ com cebola $(25 \mathrm{~g})$ e alho (15g) picados e caldo de carne (3 tabletes), logo após foram acrescentados o açúcar e a polpa de tamarindo, depois da cocção, que levou aproximadamente uns 15 minutos, foi quando começou a ferver, acrescentamos água $(600 \mathrm{~mL})$, pimenta calabresa $(15 \mathrm{~g})$ e o sal $(10 \mathrm{~g})$. Também foi adicionado o amido (100g) para se obter uma consistência mais pastosa, para isso, o amido foi primeiramente dissolvido em $100 \mathrm{~mL}$ de água, foi cozido por mais 5 minutos e então o molho foi processado no liquidificador para a homogeneização de todos os ingredientes e envazados nos potes de vidro e armazenados sob refrigeração.

A professora que coordenou essa aula prática, teve com o intuito de fabricarmos um alimento diferente do que vemos no nosso cotidiano acadêmico e pessoal, com isso, desenvolvemos um produto que fosse fácil e rápido no processo de fabricação. Dessa maneira, pensamos em um produto que seja agradável ao consumidor e que possa ser fabricado sem equipamentos sofisticados, para que esse molho pudesse ser feito em qualquer cozinha e não somente num laboratório de agroindústria.

O molho de tamarindo apresentou uma consistência gelatinosa e pastosa, uma cor marrom devido a própria cor da polpa de tamarindo, e por consequência do cozimento e por ser misturado com outros ingredientes, perdeu parcialmente sua característica de azedamento, ou seja, ficou bem agradável ao paladar sem o sabor acentuado da tamarindo, além do mais, 
comprovamos uma boa durabilidade do produto se conservado sob refrigeração.

Segundo SANTOS (2010), ao elaborar produtos, derivados da tamarindo, verificaram excelente aceitação pelos avaliadores que participaram do painel sensorial, especialmente para os produtos: barrinha de cereal, doce cremoso com batata, calda, geleia tradicional, sorvete, licor, caramelado e melado, o índice de intenção de compra e novidade foi bem aceito.

Segundo MAIA et al. (2014), a tamarindo pode ser utilizado eficientemente para produzir geleia sem adição de pectina como agente geleificante, de acordo com os resultados de análise no texturômetro e a aceitação sensorial, além disto, este tipo de alimento é uma excelente forma de conservação da fruta.

Diversos estudos apontam atividades farmacológicas relacionadas à espécie, dentre estas, anti-inflamatória e analgésica e no tratamento de dores de cabeça e sintomas de stress, por meio de compressas ou banhos, além do mais, o fruto da tamarindo tem a capacidade de geleificante em elevadas concentrações, especialmente na película que envolve a semente SILVA et al. (2015)

Imagem 2: Atividade Experimental. Fonte: Própria

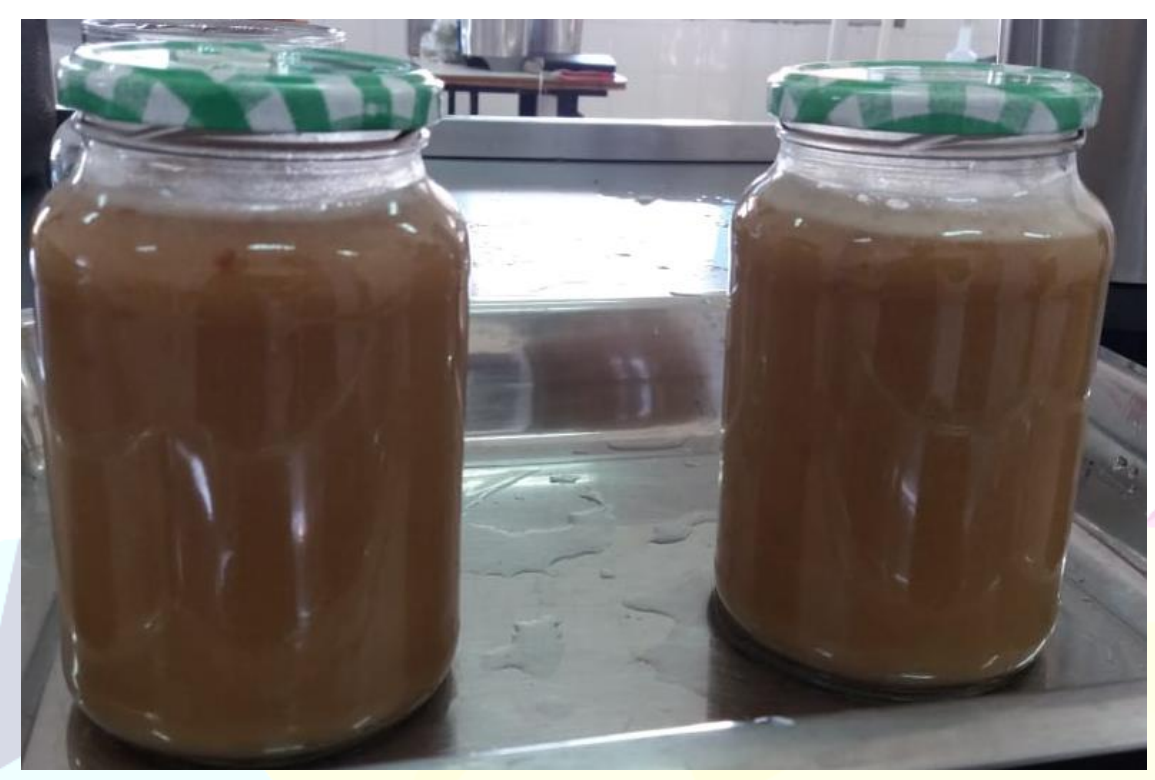

\section{CONSIDERAÇÕES}

O trabalho desenvolvido nessa aula prática foi de grande experiência para obtermos pensamento crítico sobre os alimentos que fabricamos, para que possamos ser incentivados e incentivar outros pesquisadores da área para observar a viabilidade de processar alimentos com produtos que sejam ricos nutricionalmente e pouco utilizados ou mesmo os que são descartados. É necessário abrir os horizontes para acabar com o desperdício de alimentos e para oferecer ao consumidor novas fontes de produtos. 


\section{REFERÊNCIAS}

Forma Saudável. Tamarindo. Disponível em: http://formasaudavel.com.br/tamarindo/. Acesso em 02/11/2018.

MAIA, Juliana D.; TRAVÁlIA, Beatriz M.; ANDRADE, Tamy A.; SILVA, Gleise K. C.; ANDRADE, Julianna K. S.; JÚNIOR, Antônio M. O.; MOREIRA, J. J. S. Desenvolvimento, Avaliação Físico-Química, Microbiológica E Sensorial De Geleia De Tamarindo. Revista GEINTEC - ISSN: 2237-0722. São Cristóvão/SE -2014. Vol. 4/n.1/ p.632-641.

SAIDESWARA RAO, Y.; MARY MATHEW, K. 26 - Tamarind. In: PETER, K. V. (Ed.). Handbook of Herbs and Spices (Second Edition): Woodhead Publishing, 2012. p.512-533. ISBN 978-0-85709-040-9.

SANTOS, Tatiane D.; SILVA, Izis R.; AZEVEDO, Luciana C.; RAMOS, Marta E. C. Produção E Avaliação sensorial De Produtos Elaborados Com O Fruto Do Tamarindo (Tamarindus Indica L). Publicado 2010.

SILVA, Renata A. L.; SOARES, Joyce D. R.; DIAS, Gabrielen M. G.; PASQUAL, Moacir; CHAGAS, Edvan A.; GAVILANES, Manuel L. Cultivo de tamarindo sob malhas coloridas: plasticidade anatômica foliar. Ciência Rural, Santa Maria, v.45, n.2, p.238-244, fev, 2015. 